\title{
International Association for Hospice and Palliative Care Position Statement: Euthanasia and Physician-Assisted Suicide
}

\author{
Liliana De Lima, MHA, ${ }^{1}$ Roger Woodruff, MD, Katherine Pettus, PhD, Julia Downing, RN, PhD, \\ Rosa Buitrago, $\mathrm{MCPH}^{4}$, Esther Munyoro, MD, Chitra Venkateswaran, MD, \\ Sushma Bhatnagar, MD, and Lukas Radbruch, $\mathrm{MD}^{8}$
}

\begin{abstract}
Background: Reports about regulations and laws on Euthanasia and Physician Assisted Suicide (PAS) are becoming increasingly common in the media. Many groups have expressed opposition to euthanasia and PAS while those in favor argue that severely chronically ill and debilitated patients have a right to control the timing and manner of their death. Others argue that both PAS and euthanasia are ethically legitimate in rare and exceptional cases. Given that these discussions as well as the new and proposed laws and regulations may have a powerful impact on patients, caregivers, and health care providers, the International Association for Hospice and Palliative Care (IAHPC) has prepared this statement.

Purpose: To describe the position of the IAHPC regarding Euthanasia and PAS.

Method: The IAHPC formed a working group (WG) of seven board members and two staff officers who volunteered to participate in this process. An online search was performed using the terms "position statement", "euthanasia" "assisted suicide" "PAS" to identify existing position statements from health professional organizations. Only statements from national or pan-national associations were included. Statements from seven general medical and nursing associations and statements from seven palliative care organizations were identified. A working document including a summary of the different position statements was prepared and based on these, an initial draft was prepared. Online discussions among the members of the WG took place for a period of three months. The differences were reconciled by email discussions. The resulting draft was shared with the full board. Additional comments and suggestions were incorporated. This document represents the final version approved by the IAHPC Board of Directors.

Result: IAHPC believes that no country or state should consider the legalization of euthanasia or PAS until it ensures universal access to palliative care services and to appropriate medications, including opioids for pain and dyspnea.

Conclusion: In countries and states where euthanasia and/or PAS are legal, IAHPC agrees that palliative care units should not be responsible for overseeing or administering these practices. The law or policies should include provisions so that any health professional who objects must be allowed to deny participating.
\end{abstract}

Keywords: bioethics; euthanasia; physician-assisted suicide

\footnotetext{
${ }^{1}$ International Association for Hospice and Palliative Care, Houston, Texas.

${ }^{2}$ Department of Palliative Care, Austin Health, Heidelberg, Victoria.

${ }^{3}$ Department of Medicine, Makerere University, Kampala, Uganda.

${ }^{4}$ School of Pharmacy, Universidad de Panama, Panama City, Panama.

${ }^{5}$ Department of Pain and Palliative Care Unit, Kenyatta National Hospital, Nairobi, Kenya.

${ }^{6}$ MEHAC Foundation, Kerala, India.

${ }^{7}$ Department of Pain and Palliative Care Unit, All India Institute of Medical Sciences, New Delhi, India.

${ }^{8}$ Palliative Care Centre, Malteser Hospital Bonn, Bonn, Germany.

Accepted September 23, 2016.
}

(C) Liliana De Lima et al., 2016; Published by Mary Ann Liebert, Inc. This Open Access article is distributed under the terms of the Creative Commons Attribution Noncommercial License (http://creativecommons.org/licenses/by-nc/4.0/) which permits any noncommercial use, distribution, and reproduction in any medium, provided the original author(s) and the source are credited. 


\section{Background}

$\mathbf{R}$ EPORTS ABOUT DISCUSSIONS on regulations and laws on euthanasia and physician-assisted suicide (PAS) in different countries are becoming increasingly common in the media. ${ }^{1-3}$ Many groups have expressed strong moral opposition to legalizing intentionally ending a human life by a health professional. ${ }^{4,5}$ Some argue that allowing an exception to society's long-standing prohibitions against assisting suicide or directly causing another's death is immoral, would severely erode trust in clinicians, and/or would facilitate justification for ending the life of vulnerable persons. ${ }^{6}$ Those in favor argue that severely chronically ill and severely debilitated patients have a right to control the timing and manner of their death, and thus, PAS, or both PAS and euthanasia, should be legally permissible. ${ }^{7,8}$ Still others argue that both PAS and euthanasia are ethically legitimate in rare and exceptional cases, but that professional standards and the laws should not be changed to authorize either practice. ${ }^{9}$

Given that these discussions as well as the new and proposed laws and regulations may have a powerful impact on patients, caregivers, and healthcare providers and affect the nature of their relationships in as yet unknown ways, the International Association for Hospice and Palliative Care (IAHPC) has prepared this statement.

\section{Purpose}

The purpose of this white paper is to describe the position of the IAHPC regarding euthanasia and PAS.

The secondary objectives of this paper are as follows.

- Present current definitions to which the IAHPC adheres.

- Identify recommendations from other palliative care and relevant organizations.

- Provide guidance to palliative care professionals.

\section{About IAHPC}

The IAHPC is a membership organization with no political or religious affiliations, dedicated to the global advancement and development of palliative care. The IAHPC works with governments, civil society organizations, professional associations, agencies, and individuals, to improve knowledge, increase access to resources, and foster opportunities in palliative care education, research, and training.

As an organization in formal relationship with the World Health Organization (WHO), the IAHPC serves as adviser and observer to relevant discussions and expert committees. It does not have any formal relationship with or representation in any organizations either favoring or opposing euthanasia or PAS.

The board of directors of IAHPC that comprised 15 individuals nominated by the membership is the governing body of the organization. The board includes palliative care providers from different professions (nursing, oncology, palliative medicine, pharmacy, psychiatry, and psychology) from 10 different countries (Argentina, Australia, Germany, India, Kenya, Panama, Uganda, United Kingdom, United States, and Vietnam). ${ }^{10}$ Directors serve on the board as individuals not representing his/ her employer or any other group. Currently, more than 1000 individuals from 104 countries and institutions from 40 countries are IAHPC members. ${ }^{11}$ Membership is open to any person or institution who shares the IAHPC mission. Membership fees are based on the countries' gross income level to facilitate broad geographical inclusion. Additional information about the IAHPC, its programs and members, is available on the IAHPC website at <http://hospicecare.com/home/>

\section{Methodology}

During a meeting of the IAHPC board of directors in 2015 in Copenhagen, the directors decided to develop a position statement on euthanasia and PAS.

The IAHPC formed a working group (WG) of seven board members and two staff officers who volunteered to participate in this process. Members of the WG included four palliative care physicians (R.W., E.M., S.B., and L.R.), one nurse (J.D.), one pharmacist (R.B.), one psychiatrist (C.V.), one psychologist (L.D.L.) and one political scientist (K.P.).

First, a general online search was performed using the terms "position statement," "euthanasia," "assisted suicide," and "PAS" to identify existing position statements from health professional organizations. Only statements from national or pan-national associations were included. Statements from seven general medical and nursing associations and statements from seven palliative care organizations were identified. $^{12-25}$ An initial working document, including a summary of the different position statements, was used as baseline information for the first draft and based on these, an initial draft was prepared by the WG. Additional articles on trends, attitudes, and recommendations were also identified. ${ }^{26-28}$ Online discussions among the members of the WG took place for a period of three months. The differences were reconciled by e-mail discussions until there was consensus on the statements and wording. The resulting draft statement was shared with the full board and additional comments and suggestions were incorporated. This document represents the final version approved by the IAHPC Board of Directors.

\section{IAHPC Foundational Values}

This position statement is grounded in the core values of IAHPC as expressed in the vision and mission statements.

\section{IAHPC vision}

Universal access to high-quality, palliative care, integrated into all levels of healthcare systems in a continuum of care with disease prevention, early diagnosis, and treatment, to assure that patients' and family caregivers' suffering is relieved to the greatest extent possible.

\section{IAHPC mission}

To improve the quality of life of adults and children with life-threatening conditions, and their families' quality of life, by the following:

1. Facilitating and supporting palliative care training at all levels of healthcare systems.

2. Providing guidance and technical assistance with palliative care, advocacy, clinical guidelines, and service implementation, including assistance to governments and nongovernmental organizations.

3. Fostering palliative care research and evidence-based practice. 
4. Facilitating collaboration between hospice and palliative care providers, organizations, institutions, and individuals.

\section{Palliative Care}

For the purpose of developing this position statement, the underlying discussions were based on the WHO definition of palliative care $^{29}$ :

"Palliative Care is an approach that improves the quality of life of patients and their families facing the problem associated with life-threatening illness, through the prevention and relief of suffering by means of early identification and impeccable assessment and treatment of pain and other problems, physical, psychosocial and spiritual."

Palliative care is whole-person centered care. It is delivered ideally by a team of health professionals who are dedicated to addressing the needs of patients, caregivers, and relatives. The basic tenets of palliative care, including symptom control, psychological and spiritual well-being, and care of the family, fit the goal of helping patients to live with dignity until their death. In many circles, the term "death with dignity" is also used to describe PAS and euthanasia. ${ }^{30,31}$ For the purpose of this statement "death with dignity" is referred to as death that follows after bedside palliative care for terminally ill patients.

Adequate palliative care delivery in a country requires the four components of the WHO palliative care public health strategy: (1) Adequate healthcare policies, (2) education of health providers, legislators, and the public in general, (3) availability of medications, and (4) implementation of services in all levels of care. ${ }^{32}$

According to the WHO recommendations and a World Health Assembly Resolution, ${ }^{33}$ national governments must ensure access to palliative care and to essential medicines, including immediate release of oral morphine, for relief of pain and suffering. ${ }^{34}$ Failure to do so violates the right to health and freedom from cruel, inhumane, and degrading treatment. ${ }^{35}$

\section{Evidence of unmet needs}

Throughout the world, many patients present to their healthcare system late, when their disease is advanced and therapies to control it are frequently ineffective. ${ }^{32}$ Tragically, although the knowledge and skills to control pain and diminish suffering exist, most of the world's population has no access to palliative care. The greatest need is in low- and middle-income countries, where $78 \%$ of adults in need of palliative care live and healthcare resources are the scarcest. ${ }^{36}$

Opioids are used in palliative care for the treatment of severe pain and dyspnea. The WHO has included a number of medicines, including opioids (morphine, oxycodone, and hydromorphone), for pain treatment and palliative care in the WHO Model List of Essential Medicines. ${ }^{37}$ The reported consumption of opioids to the International Narcotics Control Board (INCB) has been used as an indicator of access to palliative care.

According to the INCB, high-income countries (HIC) consume $90 \%$ of opioid analgesics. Despite reports in the mainstream media on diversion of opioids in some HIC (particularly in the United States), access to these medications for legitimate medical needs is extremely inadequate ${ }^{38-45}$ and more than $80 \%$ of the legitimate global need for opioids for medical purposes is unmet. $^{46-49}$ Studies also indicate that patients who do not have access to pain relief are at an increased risk for suicide and hastened death. ${ }^{50}$ Within this context of inadequate access to essential medicines for pain relief and other conditions, the IAHPC strongly maintains that laws or policies allowing euthanasia or PAS should never be considered as alternatives to policies supporting palliative care.

The challenges and obstacles to accessing pain treatment have been reported and described in the literature, including unduly restrictive regulations in national policies; limited knowledge and societal attitudes; socioeconomic conditions; and the high cost of medications. ${ }^{51}$

The IAHPC maintains that in accordance with guidance from the WHO recommendations ${ }^{34}$ and the WHA Resolution, national governments must take steps to ensure that people have adequate access to treatment for moderate to severe pain, and ensure availability of and access to essential opioids such as immediate release oral morphine. Their failure to do so violates their obligation to protect, respect, and fulfill the right to health and to prohibit cruel, inhuman, and degrading treatment. ${ }^{35,52}$

\section{Definitions}

There are several definitions of euthanasia and PAS in the literature. The IAHPC has adapted the definitions of the European Association for Palliative Care (EAPC) publication: "Euthanasia and physician-assisted suicide: A white paper from the European Association for Palliative Care', 12 (Table 1).

\section{Table 1. Definition of Terms (AdApted From the EAPC) ${ }^{12}$}

Euthanasia

Assisted suicide

Physician-assisted suicide

Nontreatment decisions

Palliative sedation
A physician (or other person) intentionally ending the life of a person by the administration of drugs, at that person's voluntary and competent request.

A person intentionally helping another person to terminate his or her life, at that person's voluntary and competent request.

A physician intentionally helping a person to terminate his or her life by providing drugs for self-administration, at that person's voluntary and competent request.

Withholding or withdrawing medical treatment from a person either because of medical futility or at that person's voluntary and competent request.

The monitored use of medications intended to induce a state of decreased or absent awareness (unconsciousness) to relieve the burden of otherwise intractable suffering in a manner that is ethically acceptable to the patient, family and healthcare providers.

EAPC, European Association for Palliative Care. 


\section{Position}

The IAHPC believes that no country or state should consider the legalization of euthanasia or PAS until it ensures universal access to palliative care services and to appropriate medications, including opioids for pain and dyspnea.

The IAHPC supports the EAPC position statement on euthanasia and PAS described in the publication: "Euthanasia and physician-assisted suicide: A white paper from the European Association for Palliative Care". ${ }^{12}$ Specifically, the IAHPC asserts the following:

- Withholding or withdrawing ineffective, futile, burdensome, and unnecessary life-prolonging procedures or treatments does not constitute euthanasia or PAS because it is not intended to hasten death, but rather indicate the acceptance of death as a natural consequence of the underlying disease progression.

- In some countries, voluntary euthanasia, nonvoluntary euthanasia (the patient is unable to consent), or involuntary euthanasia (against the person's will) are all recognized as forms of euthanasia. However, the IAHPC believes that nonvoluntary or involuntary forms of euthanasia should not be recognized and must never be permitted. ${ }^{53}$

- Palliative sedation-sedation intended to relieve refractory distress of a dying patient and not to hasten death-is not euthanasia or PAS. ${ }^{54,55}$ Distinguishing palliative sedation from euthanasia and PAS is based on the ethical principles of beneficence (duty to alleviate suffering) and nonmaleficence (duty to prevent or avoid harm). It should never be used with the intention to shorten life.

The IAHPC also supports the International Children's Palliative Care Network position, which states that "enabling good quality of life cannot include hastening death, and we do not believe that euthanasia or physician-assisted suicide is part of children's palliative care.",13

\section{Guiding Principles}

Arguments in favor of euthanasia and PAS focus on relieving intolerable suffering. Proponents maintain that a small percentage of severely ill or dying patients experience excruciating suffering despite all the best efforts to palliate, and ending life may be the only option to end that suffering. Others argue that any patient, who deems his or her quality of life unacceptably poor, should have the option of PAS or euthanasia. Respect for patient autonomy is also used as an argument to justify euthanasia or PAS for patients who have decided that they prefer to end life, a decision that is often related to the patient's perception of a loss of control. ${ }^{56}$

Palliative care offers a number of medical and nonmedical strategies to help relieve suffering and improve the perceived loss of control. For most patients, basic palliative care interventions are effective and may be applied at home or in inexpensive, low technical settings. ${ }^{57,58}$ Some patients may require specialized, multiprofessional, and interdisciplinary palliative care teams for the alleviation of complex symptoms or problems. In rare cases when physical, psychosocial, or spiritual distress is refractory to all other palliative efforts, palliative sedation is an effective option of last resort. ${ }^{55,59,60}$
Sedation should be discussed with the patient or legal guardian and approval must be obtained before implementing it. Some patients may reject this option and their wishes must be respected.

The request of a competent patient, or a patient's surrogate decision-maker, to withhold or withdraw any life-sustaining treatments should be respected. These treatments may include ventilatory support, pacemaker therapy, hemodialysis, antibiotics, artificial nutrition, artificial hydration, or others. In some circles, the withholding or withdrawal of treatment is confounded with a form of hastened death. While the impact of such approach may hasten death, it is not through the administration of substances, but rather by allowing the underlying disease or another condition to continue its course. Discussion of these nontreatment decisions is part of regular palliative care.

It is also part of standard palliative care to listen respectfully to patients wishing for hastened death (including requests for euthanasia and PAS). In the discussion of these wishes with patients, it becomes clear that only very rarely is this wish a request to act. Healthcare professionals should acknowledge these wishes and requests, and interpret them as the starting point of holistic care, with adequate symptom control to relieve suffering, adequate psychosocial and spiritual care, and intense communication to better understand the patient's underlying motivations and attitudes.

Many patients may lack information, have erroneous ideas about the progression of the disease, or have terrifying images of complications expected in the future course of the disease. ${ }^{61,62}$ For these patients it is not their current condition but the anticipated suffering and fear that trigger the wish for hastened death. These have to be acknowledged and discussed with the patient and appropriate psychosocial and spiritual care offered and provided.

For other patients, the wish for hastened death is not caused by physical suffering or existential distress, but is based on fear of the loss of control. This is often linked to the fear of becoming a burden to the family. ${ }^{63}$ Even if this is understandable to some degree, the IAHPC believes it is unacceptable to argue that the desire to relieve the burden onto others constitutes a legitimate reason for euthanasia or PAS. The IAHPC believes that healthcare systems should be prepared to respond to such needs and that communities and caregivers should be prepared to share the care of people with life-limiting illnesses.

There are a few patients with a very strong focus on selfsufficiency and self-determination who may feel that keeping control over the timing and method of the end of life may be the only option left to them to fulfill this need. ${ }^{4,64}$ Voluntary cessation of fluid or nutrition intake may offer an alternative for these patients, using appropriate and adequate symptom control measures.

\section{Professional Standards and Obligations}

There are additional assertions and guiding principles against the practices of euthanasia and PAS, such as physicians' professional ethical codes, the need to maintain public trust, and the WHO definition of palliative care. These are reflected in the core values of the IAHPC and are the basis of the IAHPC Position Statement. 


\section{The WHO definition}

As stated previously in this document, the WHO defines palliative care as an approach that improves the quality of life of patients and their families facing problems associated with life-threatening illness, through the prevention and relief of suffering by means of early identification and impeccable assessment and treatment of pain and other problems, physical, psychosocial, and spiritual. ${ }^{65}$ This definition regards dying as a normal process and emphasizes that palliative care never intends to hasten nor postpone death. Euthanasia and PAS are in direct conflict with this definition.

\section{Professional ethical codes}

Throughout the world, physicians are trained to provide care and preserve life. Starting with the Hippocratic Oath ("I will give no deadly medicine to anyone if asked, nor suggest any such counsel") $){ }^{66}$ professional ethical codes for physicians have clarified that ending life is not part of the tasks of a physician. The American Medical Association states that euthanasia 14 and PAS ${ }^{15}$ are "fundamentally incompatible with the physician's role as healer, would be difficult or impossible to control, and would pose serious societal risks." The World Medical Association stated that "Euthanasia, that is the act of deliberately ending the life of a patient, even at the patient's own request or at the request of close relatives, is unethical. This does not prevent the physician from respecting the desire of a patient to allow the natural process of death to follow its course in the terminal phase of sickness.", 16 Similarly, the World Medical Association states on PAS that "Physician assisted suicide, like euthanasia, is unethical and must be condemned by the medical profession. Where the assistance of the physician is intentionally and deliberately directed at enabling an individual to end his or her own life, the physician acts unethically. However, the right to decline medical treatment is a basic right of the patient and the physician does not act unethically even if respecting such a wish results in the death of the patient." 17 IAHPC believes that practicing euthanasia and PAS would violate these professional standards.

\section{The need to maintain public trust}

Within the profession of medicine, the physician-patient relationship is paramount. The IAHPC believes that practices of euthanasia and PAS violate the bond of trust within the profession of medicine, which is essential to the physicianpatient relationship. The IAHPC is concerned that these practices could erode the physician-patient relationship, that patients may be reluctant to receive palliative care treatment for the fear that physicians will hasten death. The IAHPC believes that euthanasia and PAS undermine the integrity of the profession and the dedication to safeguard human life. The IAHPC is also in agreement with the EAPC in respecting individual opinions regarding euthanasia and PAS while stressing the responsibility of all societies to provide care for their most vulnerable citizens, including the older, terminally ill, the ethnic minorities, the mentally ill, the children, and the disabled. A major component in achieving this is the establishment of palliative care within the mainstream healthcare systems of all countries by designating the necessary budgets to ensure safe access to opioids, adequate care provision, and by incorporating changes in curricula in health careers.

In states and countries where euthanasia and/or PAS are legal, the IAHPC agrees that palliative care units should not be responsible for overseeing or administering these practices as doing so would place the professionals, their staff and, in some cases, their patients and families, in untenable positions. ${ }^{67}$ The IAHPC also agrees with the Canadian Society of Palliative Care Physicians and Palliative Care Australia, which state that euthanasia and assisted suicide should not be part of palliative care practice and that "palliative care physicians should not be the gatekeepers in accessing this service. A separate approval, monitoring, and oversight body or organization is required and should be put in place", 22,68 And finally, the law or policies should include provisions so that any health professional who objects to assisting in a patient's death must be allowed to deny participating and to direct that patient to a neutral advocate who can discuss options and arrange a transfer if necessary.

\section{Acknowledgments}

The authors are grateful to the IAHPC Board of Directors for their suggestions and edits to the manuscript, in particular with Doctors Eric Krakauer and Derek Doyle for their excellent contributions to this white paper.

\section{Author Disclosure Statement}

No competing financial interests exist.

\section{Recommended Reading}

1. European Association for Palliative Care: Euthanasia and physician-assisted suicide: a white paper from the EAPC. ${ }^{27}$

2. International Children's Palliative Care Network Position Statement on the practice of Euthanasia and Assisted Suicide. ${ }^{31}$

3. World Medical Association's Declaration on Euthanasia Reaffirmation. $^{34}$

4. World Medical Association's Statement on PhysicianAssisted Suicide - Reaffirmation. ${ }^{35}$

5. World Health Assembly: Resolution on Palliative Care. ${ }^{6}$

6. World Health Organization: Definition of palliative care. ${ }^{3}$

\section{References}

1. Google: Euthanasia news. http://bit.ly/1r5ciJs (Last accessed April 22, 2016).

2. Google: Physician assisted suicide news. http://bit.ly/ 1TrUXU2 (Last accessed April 22, 2016).

3. PROCON.org Euthanasia \& Physician-Assisted Suicide (PAS) around the World. Legal Status in 28 Countries from Australia to Uruguay. http://euthanasia.procon.org/view .resource.php?resourceID=000136 (Last accessed May 21, 2016).

4. Emanuel EJ, et al.: Attitudes and practices of Euthanasia and physician-assisted suicide in the United States, Canada, and Europe. JAMA 2016;316:79-90.

5. McCormack R, Clifford M, Conroy M: Attitudes of UK doctors towards euthanasia and physician-assisted suicide: A systematic literature review. Palliat Med 2012;26: 23-33. 
6. Yang YT, Curlin FA: Why physicians should oppose assisted suicide. JAMA 2016;315:247-248.

7. Downar J, Boisvert M, Smith D: Data to support assisted dying Letter to the editor. BMJ 2014;349:g4966.

8. The World Federation of Right to Die Societies: Manifesto. www.worldrtd.net/manifesto (Last accessed April 20, 2016).

9. Task Force on Life and the Law: When death is sought: Assisted suicide and euthanasia in the medical context. NY State Department of Health. www.health.ny.gov/regulations/ task_force/reports_publications/when_death_is_sought (Last accessed April 22, 2016).

10. About IAHPC: Board of directors. http://hospicecare.com/ about-iahpc/who-we-are/board-of-directors (Last accessed August 22, 2016).

11. IAHPC Members List: http://hospicecare.com/memberssection/iahpc-members-list (Last accessed August 22, 2016).

12. Radbruch L, Leget C, Bahr P, et al.; Board Members of the EAPC: Euthanasia and physician-assisted suicide: A white paper from the European Association for Palliative Care. Palliat Med 2016;30:104-116.

13. International Children's Palliative Care Network: International Children's Palliative Care Network (ICPCN) Position Statement on the practice of Euthanasia and Assisted Suicide. 2014. www.icpen.org/wp-content/uploads/2013/07/ICPCN-PositionPaper-on-Euthanasia-in-Childrens-Palliative-Care.pdf (Last accessed March 21, 2016).

14. American Medical Association: Opinion 2.21-Euthanasia. www.ama-assn.org/ama/pub/physician-resources/medicalethics/code-medical-ethics/opinion221.page? 1996. (Last accessed March 21, 2016).

15. American Medical Association: Opinion 2.211-Physicianassisted suicide. 1996. www.ama-assn.org/ama/pub/physicianresources/medical-ethics/code-medical-ethics/opinion2211 .page? (Last accessed March 21, 2016).

16. World Medical Association: World medical association's declaration on Euthanasia-Reaffirmation. World Medical Association, 2015. www.wma.net/en/30publications/10policies/e13/ index.html (Last accessed April 21, 2016).

17. World Medical Association: Statement on physicianassisted suicide-Reaffirmation. World Medical Association, 2015. www.wma.net/en/30publications/10policies/p13/index .html (Last accessed April 21, 2016).

18. American Nurses Association: Position statement-Euthanasia, assisted suicide and aid in dying, 2013. www.nursingworld .org/MainMenuCategories/EthicsStandards/Ethics-PositionStatements/Euthanasia-Assisted-Suicide-and-Aid-in-Dying .pdf (Last accessed April 22, 2016).

19. American Academy of Hospice and Palliative Medicine: Statement on physician assisted dying, 2016. http://aahpm .org/positions/pad (Last accessed April 22, 2016).

20. National Hospice and Palliative Care Organization: Commentary and resolution on physician assisted suicide, 2005. www.nhpco.org/sites/default/files/public/PAS_Resolution_ Commentary.pdf (Last accessed April 22, 2016).

21. Hospice and Palliative Nurses Association: Position statement on legalization of assisted suicide, 2011. http://hpna .advancingexpertcare.org/wp-content/uploads/2014/09/HPNALegalization-of-Assisted-Suicide-Position-Statement-080311 .pdf (Last accessed April 22, 2016).

22. Palliative Care Australia: Euthanasia and physician assisted suicide. Position Statement, 2011. http://palliativecare.org.au/ wp-content/uploads/2015/08/PCA-position-statement-Euthan asia-and-Physician-Assisted-Suicide.pdf (Last accessed April 22, 2016).
23. Canadian Society of Palliative Care Physicians: Position on Euthanasia and assisted suicide, 2015. www.cspcp.ca/wpcontent/uploads/2014/10/CSPCP-Position-on-Euthanasiaand-Assisted-Suicide-Feb-6-2015.pdf (Last accessed April 22, 2016).

24. Royal College of Nursing Australia: Voluntary Euthanasia/ assisted suicide position statement. http://mail.rcna.org.au/imis 15/Images/RCNA_website/Files\%20for\%20upload\%20and\%20 link/policy/documentation/position/voluntary_euthanasia.pdf (Last accessed April 22, 2016).

25. British Medical Association: Physician assisted dying-Position statement, 2012. www.bma.org.uk/advice/employment/ethics/ ethics-a-to-z/physician-assisted-dying (Last accessed April 22, 2016).

26. Steck N, Egger M, Maessen M, et al.: Euthanasia and assisted suicide in selected European countries and US states: Systematic literature review. Med Care 2013;51:938-944.

27. Chambaere K, Bilsen J, Cohen J, et al.: Physician-assisted deaths under the euthanasia law in Belgium: A populationbased survey. Can Med Assoc J 2010;182:895-901.

28. Onwuteaka-Philipsen BD, Brinkman-Stoppelenburg A, Penning $\mathrm{C}$, et al.: Trends in end-of-life practices before and after the enactment of the euthanasia law in the Netherlands from 1990 to 2010: A repeated cross-sectional survey. Lancet 2012; 380:908-915.

29. World Health Organization: National Cancer Control Programs: Policies and Managerial Guidelines, 2nd ed. Geneva: WHO, 2002.

30. Guo Q, Jacelon CS: An integrative review of dignity in end-of-life care. Palliat Med 2014;28:931-940.

31. Chochinov H: Dignity-conserving care-A new model for palliative care: Helping the patient feel valued. JAMA 2002; 287:2253-2260.

32. Stjernsward J, Foley KM, Ferris FD: The public health strategy for palliative care. J Pain Symptom Manage 2007;33: 486-493.

33. World Health Assembly: Strengthening of palliative care as a component of comprehensive care within the continuum of care. Geneva: World Health Organization, 2014. http://apps .who.int/gb/ebwha/pdf_files/WHA67/A67_R19-en.pdf (Last accessed April 22, 2016).

34. World Health Organization: Ensuring Balance in National Policies on Controlled Substances-Guidance for Availability and Accessibility of Controlled Medicines. Geneva: WHO Press, 2011.

35. Human Rights Watch: "Please, Do Not Make Us Suffer Any More..." Access to Pain Treatment as a Human Right. New York; HRW, 2009.

36. Worldwide Palliative Care Alliance: Global atlas of palliative care at the end of life. 2014. www.who.int/nmh/ Global_Atlas_of_Palliative_Care.pdf (Last accessed March 16, 2015).

37. World Health Organization: WHO model list of essential medicines-19th edition, 2015. www.who.int/medicines/ publications/essentialmedicines/en (Last accessed April 12, 2016).

38. International Narcotics Control Board: Availability of Internationally Controlled Drugs: Ensuring Adequate Access for Medical and Scientific Purposes.Vienna: INCB, 2016.

39. Cleary J, Powell RA, Munene G, et al.: Formulary availability and regulatory barriers to accessibility of opioids for cancer pain in Africa: A report from the Global Opioid Policy Initiative (GOPI). Ann Oncol 2013;24:xi14-xi23. 
40. Cleary J, De Lima L, Eisenchlas J, et al.: Formulary availability and regulatory barriers to accessibility of opioids for cancer pain in Latin America and the Caribbean: A report from the Global Opioid Policy Initiative (GOPI). Ann Oncol 2013;24:xi41-xi50.

41. Cleary J, Silbermann M, Scholten W, et al.: Formulary availability and regulatory barriers to accessibility of opioids for cancer pain in the Middle East: A report from the Global Opioid Policy Initiative (GOPI). Ann Oncol 2013;24(Suppl 11):xi51-xi59.

42. Cleary J, Simha N, Panieri A, et al.: Formulary availability and regulatory barriers to accessibility of opioids for cancer pain in India: A report from the Global Opioid Policy Initiative (GOPI). Ann Oncol 2013;24(Suppl 11):xi33-xi40.

43. Cleary J, Radbruch L, Torode J, Cherny NI: Formulary availability and regulatory barriers to accessibility of opioids for cancer pain in Asia: A report from the Global Opioid Policy Initiative (GOPI). Ann Oncol 2013;24(Suppl 11):xi24-xi32.

44. Cherny NI, Baselga J, de Conno F, Radbruch L: Formulary availability and regulatory barriers to accessibility of opioids for cancer pain in Europe: A report from the ESMO/EAPC Opioid Policy Initiative. Ann Oncol 2010;21:615-626.

45. Berterame S, Erthal J, Thomas J, et al.: Use of and barriers to access to opioid analgesics: A worldwide, regional, and national study. Lancet 2016;387:1644-1656.

46. Human Rights Watch: Abandoned in agony-Cancer and the struggle for pain treatment in Senegal. New York, 2013. www.hrw.org/report/2013/10/24/abandoned-agony/cancerand-struggle-pain-treatment-senegal (Last accessed April 24, 2016).

47. Human Rights Watch: Uncontrolled Pain: Ukraine's Obligation to Ensure Evidence-Based Palliative Care. New York; HRW, 2011.

48. Human Rights Watch: Care where there is no cureEnsuring the right to palliative care in Mexico. New York, 2014. http:// features.hrw.org/features/HRW_2014_report/Mexico_Care_ When_There_Is_No_Cure/index.html (Last accessed April 24, 2016).

49. Human Rights Watch: Pain tears me apart-Challenges and progress in ensuring the right to palliative care in Morocco. New York, 2016.www.hrw.org/sites/default/files/report_pdf/ morocco0216_web.pdf (Last accessed April 11, 2016).

50. Krakauer EL, Wenk R, Buitrago R, et al.: Opioid inaccessibility and its human consequences: Reports from the field. J Pain Palliat Care Pharmacother 2010;24:239-243.

51. De Lima L, Pastrana T, Radbruch L, Wenk R: Crosssectional pilot study to monitor the availability, dispensed prices and affordability of opioids around the globe. J Pain Symptom Manage 2014;48:649-659.

52. Radbruch L, Payne S, de Lima L, Lohmann D: The Lisbon challenge: Acknowledging palliative care as a human right. J Palliat Med 2013;16:301-304.

53. Cohen-Almagor R: First do no harm: intentionally shortening lives of patients without their explicit request in Belgium. J Med Ethics 2015;41:625-629.

54. Olsen ML, Swetz KM, Mueller PS: Ethical decision making with end-of-life care: Palliative sedation and withholding or withdrawing life-sustaining treatments. Mayo Clin Proc 2010; 85:949-954.
55. Cherny NI, Radbruch L: European Association for Palliative Care (EAPC) recommended framework for the use of sedation in palliative care. Palliat Med 2009;23:581-593.

56. Bauchner H, Fontanarosa PB: Death, dying, and end of life. JAMA 2016;315:270-271.

57. Singer AE, Goebel JR, Kim YS, et al.: Populations and interventions for palliative and end-of-life care: A systematic review. J Palliat Med 2016;19:995-1008.

58. Rabow M, Kvale E, Barbour L, et al.: Moving upstream: A review of the evidence of the impact of outpatient palliative care. J Palliat Med 2013;16:1540-1549.

59. Quill TE, Byock IR: Responding to intractable terminal suffering: The role of terminal sedation and voluntary refusal of food and fluids. ACP-ASIM end of life consensus panel. American College of Physicians-American Society of Internal Medicine. Ann Intern Med 2000;132:408-414.

60. Gauvin F, Humbert N, Marzouki M, et al.: Palliative sedation in pediatric patients: Guidelines established by the pediatric palliative consultation service at Sainte-Justine hospital. Med Palliat 2016;15:40-50.

61. Weeks JC, Catalano PJ, Cronin A, et al.: Patients' expectations about effects of chemotherapy for advanced cancer. N Engl J Med 2012;367:1616-1625.

62. Morris DA, Johnson KS, Ammarell N, et al.: What is your understanding of your illness? A communication tool to explore patients' perspectives of living with advanced illness. J Gen Intern Med 2012;27:1460-1466.

63. Ohnsorge K, Gudat H, Rehmann-Sutter C: What a wish to die can mean: Reasons, meanings and functions of wishes to die, reported from 30 qualitative case studies of terminally ill cancer patients in palliative care. BMC Palliat Care 2014;13:1.

64. Guirimand F, Dubois E, Laporte L, et al.: Death wishes and explicit requests for euthanasia in a palliative care hospital: An analysis of patients files. BMC Palliat Care 2014;13:1.

65. Sepulveda C, Marlin A, Yoshida T, Ullrich A: Palliative care: the World Health Organization's global perspective. J Pain Symptom Manage 2002;24:91-96.

66. Hippocrates. The Oath and Law of Hippocrates. Vol. XXXVIII, Part 1. The Harvard Classics. New York: P.F. Collier and Son, 1910.

67. Pereira J, Anwar D, Pralong G, et al.: Assisted suicide and euthanasia should not be practiced in palliative care units. $\mathrm{J}$ Palliat Med 2008;11:1074-1076.

68. Canadian Society of Palliative Care Physicians Submission to Special Joint Committee on Physician-Assisted Dying. January 27, 2016. www.cspcp.ca/wp-content/uploads/2016/ 01/CSPCP-Submission-to-the-Special-Joint-Committee-onPhysician-Assisted-Dying-National-Secretariat.pdf (Last accessed May 5, 2016).

Address correspondence to: Liliana De Lima, MHA International Association for Hospice and Palliative Care 5535 Memorial Drive Suite F-PMB 509 Houston, TX 77007

E-mail:1delima@iahpc.com 